\title{
ORIENTAÇÃO EMPREENDEDORA E REDES SOCIAIS: UM ESTUDO TEÓRICO-EMPÍRICO
}

\author{
Victor Corrêa ${ }^{1}$ \\ Ernesto Michelangelo Giglio ${ }^{1}$ \\ Luciana Caldara Estece ${ }^{1}$
}

\footnotetext{
${ }^{1}$ Universidade Paulista
} 


\section{ORIENTAÇÃO EMPREENDEDORA E REDES SOCIAIS: UM ESTUDO TEÓRICO-EMPÍRICO}

Resumo: Insere-se na literatura sobre empreendedorismo a noção, ainda prevalecente, que os empreendedores seriam indivíduos dotados de atributos pessoais diferenciados. Novas reflexões, contudo, vêm projetando luzes para a necessidade de se incorporar a esta figura do empreendedor atomizado a noção relacional, segundo a qual tais indivíduos se encontrariam imersos em redes socioeconômicas capazes de influenciá-los. Este artigo se insere neste contexto. Busca, de maneira inovadora nos estudos da administração, investigar possíveis associações, pouco exploradas, entre as abordagens da Orientação Empreendedora e a das Redes Sociais. Faz isto através do estudo empírico de tipo particular de empreendedor, o religioso, altamente emergente e ainda pouco investigado no Brasil. Conclui propondo nova interpretação teórica, derivada da associação entre ambas as literaturas.

Palavras-chave: Orientação Empreendedora. Redes Sociais. Empreendedorismo Religioso. Empreendedorismo.

\section{$1 \quad$ Introdução}

A literatura sobre empreendedorismo vem, sobretudo nas últimas décadas, evoluindo rapidamente (Carlsson et al., 2013; Ferreira, Pinto, \& Miranda, 2015; Ribeiro-Soriano, 2017). Com efeito, considerado um dos principais responsáveis pelo crescimento econômico (Costa, Barros, \& Martins, 2012; Kima \& Kang, 2014; Urbano \& Aparicio, 2016), um importante propulsor da geração de emprego e renda em diversos países (Costa, Barros, \& Martins, 2012; Ribeiro-Soriano, 2017), o empreendedorismo ganha destaque nas literaturas nacional e internacional (Moroz \& Hindle, 2012).

Insere-se, na essência das reflexões sobre empreendedorismo, a noção, hoje prevalecente, que os empreendedores seriam indivíduos "portadores de qualidades e habilidades excepcionais" (Colbari, 2007, p. 1), isto é, dotados de atributos capazes de diferenciá-los em relação aos demais (Baron, 2013; Hmieleski, Carr, \& Baron, 2015). Neste contexto, "o sucesso de novos empreendimentos estaria fundamentalmente associado às características comportamentais do empreendedor" (Hofer \& Sandberg, 1987). Caberia a ele a responsabilidade "de produzir cada vez mais riquezas" (Costa, Barros, \& Martins, 2012, p.362). Tal perspectiva não é necessariamente recente. Remonta à Schumpeter (1911), considerado o teórico do empreendedorismo por excelência (Martinelli, 2009). Para o autor, "o empreendedorismo é compreendido como resultado da ação de agente único: o empreendedor" (Ferrary e Granovetter, 2009, p. 327).

Diversas abordagens poderiam se inserir nesta linha de raciocínio. Entre elas, destacarse-iam, por exemplo, aquelas que enfatizam empreendedores como agentes que: i.) combinam e transformam fatores de produção na criação de bens de valor agregado (Martinelli, 2009); assumem riscos em condições de incerteza (McClelland, 1972); possuem a capacidade de tomar decisões (Nair \& Pandey, 2006); identificam e mobilizam oportunidades de mercado (Hmieleski, Carr, \& Baron, 2015; Estrin, Mickiewicz, \& Stephan, 2016; Vale, 2014); criam 
novas empresas (Shook, Priem, \& McGee, 2003); demonstram-se responsáveis pelo desenvolvimento econômico (Ribeiro-Soriano, 2017), entre outras.

Uma delas, de particular interesse para esta pesquisa, relaciona-se à vertente da $\mathrm{OE}$, altamente emergente nas ciências da administração (Adel \& Habib, 2016; Boso, Story, \& Cadogan, 2013; Cao, Simsek, \& Jansen, 2015; Martins, 2016; Nwankwo \& Gbadamosi, 2013; Nobile \& Husson, 2016; Rodrigo-Alarcón, García-Villaverde, Ruiz-Ortega, \& Parra-Requena, no prelo; Saeed, Yousafzai, \& Engelen, 2014; Shan, Song, \& Ju, 2016; Song, Min, Lee, \& Seo, 2017). De fato, salientam Shan, Song and Ju (2016) como a temática sobre OE tem recebido substancial atenção teórica e empírica nos últimos anos; como ela tem se consolidado como fator de diferenciação na literatura sobre empreendedorismo (Rodrigo-Alarcón et al., no prelo). Nela, empreendedores seriam caracterizados por suas capacidades em combinarem, de maneira distintiva, atributos pessoais considerados fundamentais ao sucesso empreendedor. Cinco deles são destacados pela literatura: capacidade de inovação, proatividade, agressividade competitiva, assunção de riscos e autonomia (Martins, 2016; Shan, Song, \& Ju, 2016).

Reflexões mais recentes, contudo, vêm projetando luzes para a necessidade de novos estudos sobre a temática do empreendedorismo (Lajqi \& Krasniqi, 2017; Martins, 2016; Smith, Smith, \& Shaw, 2017; Shan, Song, \& Ju, 2016; Stam et al. 2014; Williams, Huggins, \& Thompson, 2017). Neste contexto, "há aproximadamente 15 anos, as pesquisas sobre redes emergiram como importante área de investigação" (Hoang \& Antoncic, 2003, p. 165). Enfatizam Slotte-Kock and Coviello (2010, p. 31) como, nos últimos anos, "interesse nas redes tem permeado as pesquisas sobre o empreendedorismo"; como elas podem ser consideradas determinantes dos resultados empreendedores, um micro fundamento da ação individual (Smith, Smith, \& Shaw, 2017).

Neste cenário, diferentes autores passaram a chamar a atenção para a necessidade de se incorporar à figura do empreendedor, enquanto detentor de atributos diferenciados -, à visão generalizada dos empreendedores como atores econômicos atomizados e autossuficientes, em outras palavras (Martins, 2016; Vale, Wilkinson \& Amâncio, 2008) -, a noção, relacional, segundo a qual tais indivíduos se encontrariam, na realidade, imersos em redes socioeconômicas, capazes de influenciá-los (Lajqi \& Krasniqi, 2017; Martins, 2016; Smith, Smith, \& Shaw, 2017; Shan, Song, \& Ju, 2016; Shepherd, 2015; Song, Min, Lee, Seo, 2017; Stam et al. 2014; Williams, Huggins, \& Thompson, 2017, entre outros). Isto é, estariam intimamente atados a estruturas de relacionamentos (Lajqi \& Krasniqi, 2017; Martins, 2016; Smith, Smith, \& Shaw, 2017; Song, Min, Lee, \& Seo, 2017; Williams, Huggins, \& Thompson, 2017).

Com efeito, salientam Stam, Arzlanian and Elfring (2014) como as redes emergiram como complemento às "teorias focadas em traços individuais ao reconhecer que os empreendedores se encontram[, na realidade,] imersos em contextos sociais que estimulam ou restringem o comportamento" (Stam, Arzlanian, \& Elfring, 2014, p. 154). Já Lajqi and Krasniqi (2017, p. 387) enfatizam como os empreendedores só "podem ser compreendidos e interpretados se nós os posicionarmos dentro [...] das redes sociais, e não somente como tomadores de decisão atomizados que maximizam suas próprias utilidades". Chen and Zhou (2017, p. 1554), por sua vez, sustentam como a "ação empreendedora não é realizada somente por uma pessoa; ela requer esforço combinado de membros de um time". Finalmente, Williams, Huggins e Thompson $(2017$, p. 1) argumentam como o empreendedorismo é "inerentemente 
um processo socializado baseado em redes sociais informais que fornecem recursos valiosos". Ou seja, "empreendedores estão imersos em redes sociais que desempenham papel fundamental no processo empreendedor" (Martins, 2016, p. 21).

Este artigo, derivado de reflexões teórico-empíricas, insere-se neste contexto. Procura investigar possíveis associações, ainda pouco exploradas pela literatura, entre as abordagens da OE e a das Redes Sociais (Adel \& Habib, 2016; Liu \& Lee, 2015; Rodrigo-Alarcón et al., no prelo; Stam \& Elfring, 2014; Suyanto \& Pratono, 2016). Tal esforço se demonstra fundamental. Salientam Rodrigo-Alarcón et al. (no prelo, p. 1) como estudos sobre OE devem se mover "rumo às áreas menos exploradas, tais como capital social", por exemplo; como, ainda hoje, a temática da "orientação empreendedora permanece virtualmente intocada por pesquisas teóricas e empíricas sobre [...] redes". De fato, "uma série de abordagens teóricas tem[, ainda hoje,] negligenciado as conexões entre redes relacionais e orientação empreendedora" (Adel e Habib (2016, s/p). Tais são justamente o foco teórico deste trabalho. Busca isto através do estudo empírico de tipo particular de empreendedor, o religioso, aqui expresso no papel desempenhado por pastores evangélicos neopentecostais, de interesse particular. Enfatizam Pearce et al. (2010, p. 228) a propensão empreendedora de pastores. Em estudo deles nos Estados Unidos, concluíram os autores que pastores com maior OE possuíam organizações religiosas mais bem-sucedidas que as dos demais (Pearce et al., 2010).

Salienta-se a existência de lacunas de pesquisas, aqui focalizadas. A primeira, de natureza empírica, refere-se aos estudos sobre comportamento empreendedor. Este "tem sido [fortemente] negligenciado como tópico de pesquisa em setores não lucrativos" (Pearce et al., 2010, p. 219). O religioso é um deles. Em que pese o vigoroso crescimento da comunidade evangélica, com efeito, só na década de 1990, esta cresceu $100 \%$ (http://www.ibge.gov.br/home/, recuperado em 17 de agosto, 2017) -, aumento considerado por Pacheco et al. (2007, p.55) "o acontecimento de maior importância do Cristianismo no século passado" -, o "papel do comportamento empreendedor no contexto religioso é inexplorado" (Pearce et al., 2010, p. 228). Tal fato é particularmente verdadeiro no Brasil. Ainda "existe, no País, grandes lacunas [...] no estudo de igrejas como empreendimentos e de pastores como empreendedores" (Corrêa \& Vale, 2017a, p. 12). Este estudo inova ao projetar luzes, raramente enfatizadas, para a importância e adequação do contexto religioso brasileiro como objeto empírico de investigação por estudiosos da administração no Brasil.

A segunda, de natureza teórica, por sua vez, refere-se à associação, aqui empreendida, entre as literaturas sobre OE e redes sociais. Salientam Boso, Story, \& Cadogan (2013, p. 709) a ainda hoje necessidade de se "determinar a extensão na qual a [OE] é condicionada pelas [...] redes sociais". De fato, poucos estudos abordam a associação entre ambas as literaturas (Rodrigo-Alarcón et al., no prelo). Em busca por títulos (orientação empreendedora e redes | entrepreneurial orientation and network) realizada em algumas das principais bases de dados (Portal Capes, Spell e Web of Science), somente 16 artigos, todos internacionais, foram localizados. Nenhum deles, contudo, buscou, tal como aqui empreendido, agregar OE à temática das redes, em especial àquela relacionada ao acoplamento/desacoplamento sociais, emergente na literatura. Com efeito, salientam Corrêa and Vale (2017b, p.309) como a temática sobre "acoplamento e desacoplamento [...] não tem, até o momento, recebido o impulso necessário por parte" dos pesquisadores. Este artigo procurar explorar parte destas lacunas. A 
agregação entre as abordagens da $\mathrm{OE}$ e da do acoplamento/desacoplamento se demonstrou, aqui, altamente profícua.

Finalmente, a terceira se relaciona à metodologia de pesquisa. Estudos sobre "OE se apropriam principalmente de abordagens quantitativas" (Nobile \& Husson, 2016, p. 178). Poucos são os trabalhos que buscam, tal como aqui proposto, compreender atributos da $\mathrm{OE}$ a partir de enfoques metodológicos alternativos. Salientam Nobile and Husson (2016, p. 187) a necessidade de novos trabalhos explorarem, à análise da $\mathrm{OE}$, diferentes "métodos qualitativos, indo dos clássicos aos mais inovadores". Este artigo, ao se apropriar da estratégia qualitativa com emprego do método de estudo de caso múltiplo, insere-se no conjunto destes esforços. Endossa corrente de pesquisa que defende o estudo da $\mathrm{OE}$ a partir de diferentes abordagens metodológicas.

\section{Base Teórica}

A perspectiva que compreende a figura do empreendedor como agente atomizado, cujas características pessoais e comportamentais possibilitariam diferenciá-lo de maneira bemsucedida no mercado, vem, nos últimos anos, ganhando destaque na literatura nacional e internacional (Baron, 2013; Hmieleski, Carr, \& Baron, 2015; entre outros). Inserem-se, na origem das proposições sobre esta abordagem, reflexões de autor seminal: Schumpeter (1911). Considerado o teórico do empreendedorismo por excelência (Martinelli, 2009), Schumpeter, salientam Ferrary and Granovetter (2009, p. 327), compreendia o empreendedorismo como reflexo da "ação de agente único: o empreendedor". "Ao empreendimento de novas combinações denominamos de empresa e aos indivíduos cuja função é realizá-las, empreendedores"' (Schumpeter, 1959, p. 105). Caberia ao empreendedor o papel de promover inovações, rompendo, através da "Destruição Criativa" - isto é, da introdução contínua de "novas combinações" de bens e serviços inéditos - o que ele denominava de fluxo circular, compreendido como o equilíbrio das estruturas de mercado.

$\mathrm{Na}$ linha de abordagem Schumpeteriana, o empreendedor passou a ser compreendido como "criador ou desbravador de novas oportunidades" (Vale, Wilkinson \& Amancio, 2008, p. 8); um agente atomizado e autossuficiente, cujos atributos pessoais o diferenciariam de maneira bem-sucedida no contexto empreendedor (Baron, 2013; Hmieleski, Carr, \& Baron, 2015; Vale, Wilkinson \& Amancio, 2008). Diversas abordagens poderiam se inserir nesta linha de raciocínio. Uma delas, de particular interesse para esta investigação, relaciona-se à vertente da OE (Adel \& Habib, 2016; Boso, Story, \& Cadogan, 2013; Cao, Simsek, \& Jansen, 2015, entre outros). Nela, empreendedores, religiosos ou não (Pearce, Fritz, \& Davis, 2010), poderiam ser caracterizados pelas suas capacidades em combinarem, de maneira distintiva, atributos pessoais (Song, \& Ju, 2016) responsáveis por "fornecerem base para decisões empreendedoras" (Song, \& Ju, 2016, p. 101). Cinco deles são destacados pela literatura: capacidade de inovação, proatividade, agressividade competitiva, assunção de riscos e autonomia (Martins, 2016; Saeed, Yousafzai, \& Engelen, 2014; Shan, Song, \& Ju, 2016).

A capacidade de inovação refletiria "a tendência para engajar e suportar novas ideias, novidades, experimentações e processos criativos que podem resultar em novos produtos, serviços ou tecnologias" (Lumpkin \& Dess, 1996, p. 142). Já a proatividade se relacionaria ao ato de se antecipar problemas ou necessidades (Rodrigo-Alarcón et al., no prelo; Wiklund \& 
Shepherd, 2005; Wang, 2008). Implica agir em antecipação à demanda de mercado, desenvolvendo novos produtos ou melhorando produtos atuais à frente dos concorrentes. (Lumpkin \& Dess, 2009; Rodrigo-Alarcón et al., no prelo; Wang, 2008).

A agressividade competitiva se relaciona à "intensidade dos esforços para superar competidores" (Lumpkin \& Dess, 2001, p. 431). Isto é, sugere, através de "forte postura ofensiva" (Lumpkin \& Dess, 2001, p. 433), disposição para enfrentar empreendedores concorrentes (Rodrigo-Alarcón et al., no prelo). Salientam diferentes autores a agressividade competitiva no contexto religioso (ver, por exemplo: Finke et al., 1996). Concluem "que enquanto a forma [...] varia de sutil a manifesta, todas as denominações se esforçam para manter e crescer sua filiação através de práticas competitivas" (Pearce et al., 2010, p. 227).

A capacidade de assumir risco se referiria, por sua vez, à disposição para atuar, sob ambiente incerto, para além de práticas usualmente aceitas (Nwankwo \& Gbadamosi, 2013; Pearce et al., 2010; Rodrigo-Alarcón et al., no prelo; Wang, 2008). Representa a disposição para se buscar oportunidades, "à despeito do desconhecimento da probabilidade de seu sucesso e das consequências de suas ações" (Rodrigo-Alarcón et al., no prelo, p. 2). Finalmente, a autonomia se relaciona à capacidade de um empreendedor (Rodrigo-Alarcón et al., no prelo) "agir de maneira independente" (Pearce et al., 2010, p. 225).

A OE inserida no contexto religioso foi objeto de pesquisa quantitativa de Pearce et al. (2010). Os autores investigaram a Igreja Evangélica Luterana nos Estados Unidos. Concluíram que o estudo do "comportamento empreendedor em congregações religiosas [...] é uma iniciativa valiosa" (Pearce et al., 2010, p. 240). Isso porque, elas poderiam se beneficiar dos comportamentos empreendedores de seus pastores (Pearce et al., 2010, p. 240). Tal poderia ser, também, a realidade do contexto brasileiro. Com efeito, evidências episodiais acenam para a plausibilidade teórica de que agentes religiosos brasileiros, pastores neopentecostais, aqui de interesse particular, possuem atributos representativos da OE.

De fato, pastores evangélicos, salientam diferentes autores da sociologia e da religião no Brasil (Mariano, 2013; Passos, Zorzin, \& Rocha, 2011; Pierucci, 2008, 2011), encontram-se, atualmente, inseridos em mercado religioso de livre concorrência entre crescente número de igrejas. Resultado da secularização do Estado e da desregulação religiosa derivada daí (Mariano, 2013; Pierucci, 2008), o crescimento do pluralismo religioso acabou por implicar, no País, em "conflitividade confusamente multidirecional por conta [...] do envolvimento dos próprios agentes religiosos com a ideia mesma de competição 'legítima', 'natural' e “inevitável'” (Pierucci, 2008, p.14). Isto é, com maior oferta religiosa, pastores evangélicos, sobretudo de vertente neopentecostal, acabaram como que "mergulhados até o pescoço numa inadiável e urgentíssima disputa por mais resultados e oportunidades, [...] por mais seguidorescontribuintes" (Pierucci, 2008, p.14).

Com efeito, "em 'mercado religioso' extremamente aquecido" (Passos, Zorzin, \& Rocha, 2011, p. 704), tal como manifesto atualmente no Brasil, "aquelas igrejas, religiões [ou empreendedores] que não se mobilizam no sentido de entrar no processo concorrencial de "disputa de almas", de maneira mais incisiva, saem "perdendo" (Passos et al., 2011, p. 704). Logo, "o objetivo de quase todos parece ser só um: suas igrejas precisam crescer. Repete-se então no campo religioso brasileiro o que sempre e em toda parte é consequência de um tal processo de liberalização concorrencial: [...] Quem não cresce, encolhe" (Pierucci, 2011, p. 474). 
Observe-se como a concorrência franca acabou por resultar em pastores neopentecostais "menos acomodados, mais dinâmicos e bem-dispostos [...] na mobilização de séquitos, públicos e clientelas" (Pierucci, 1999). Tal reflexão aparenta projetar luzes para duas ideias associadas entre si: a primeira, que pastores atuam como empreendedores. A segunda, que eles seriam atomizados, detentores de características particulares capazes de projetá-los de maneira bemsucedida no contexto religioso. Tal concepção é confrontada por perspectiva dos empreendedores enquanto agentes relacionais. Nesta, prevalece a noção que os empreendedores seriam atores imersos em redes de relações sociais e econômicas. Tais redes, por sua vez, seriam capazes de influenciar os recursos nos quais os empreendedores poderiam usufruir (Martinelli, 2009).

Nesta perspectiva, há, "implicitamente, crítica à noção dominante que vê [o empreendedor] como um ator atomizado e autossuficiente" (Vale, Wilkinson \& Amancio, 2008, p. 3). Com efeito, a partir da literatura sobre redes sociais, diferentes autores passaram a chamar a atenção para a necessidade de se incorporar à figura do empreendedor enquanto detentor de atributos diferenciados -, à visão generalizada dos empreendedores como atores econômicos atomizados e autossuficientes, em outras palavras (Corrêa \& Vale, 2014; Martins, 2016; Vale, Wilkinson \& Amâncio, 2008) -, a noção, relacional, segundo a qual tais indivíduos se encontrariam, na realidade, imersos em redes sociais e econômicas, capazes de influenciálos (Martins, 2016; Smith, Smith, \& Shaw, 2017; Shan, Song, \& Ju, 2016; Stam et al. 2014; entre outros). Foi principalmente a partir de Granovetter $(1973,2009)$ que as proposições sobre o tema ganharam relevância destacada (Corrêa \& Vale, 2014).

Granovetter $(1973,2009)$ edificou duas duplas de conceitos, a de laços fortes e fracos (1973), e a de acoplamento e desacoplamento sociais (2009), aqui de foco particular. Segundo o autor, laços fortes seriam constituídos por contatos frequentes e de longa duração entre dois (díades) ou mais indivíduos (Granovetter, 1973), formando redes sociais densas. Já os laços fracos seriam caracterizados por relacionamentos pouco frequentes, usualmente de curta duração (Granovetter, 1973). Originários de redes sociais distintas, estes gerariam, em detrimento aos laços fortes, recursos inéditos, extrapolados àqueles disponíveis no conjunto de relacionamentos no qual o empreendedor encontra-se imerso (Granovetter, 1973).

Posteriormente, Granovetter avança em suas proposições sobre laços sociais ao criar uma tipologia fundamentada em dois conceitos principais: acoplamento e desacoplamento. $\mathrm{O}$ primeiro sinalizaria para a relevância da presença de redes dotadas de forte interação entre atores, e, consequentemente, de maior coesão interna. Já o desacoplamento, por sua vez, sugeriria redes menos densas e mais fragmentadas. Conclui o autor a importância de, para o desenvolvimento de empreendimentos bem-sucedidos, imersos em diferentes contextos dentre os quais poderia se inserir o religioso - haver adequado equilíbrio entre acoplamento e desacoplamento; isto é, a presença, simultânea, de certo grau entre ambos. "Tão importante quanto a intensidade de interação é o limite claramente definido a partir do qual tal intensidade e confiança caem acentuadamente" (Granovetter, 2009, p. 255).

De fato, enquanto acoplamento geraria o que o autor denomina de "solidariedade horizontal", isto é, a presença de laços de confiança, fundamentais à geração de recursos de diferentes ordens; desacoplamento, por sua vez, indicaria a relevância de se manter, ao mesmo tempo, certo afastamento, desconexão ou desvinculação social, fundamentais em determinadas situações. Salienta Granovetter (2009) como este relativo afastamento social permitiria ao 
empreendedor evitar o que ele denomina de "solidariedade descontrolada", os abusos, advindos sobretudo dos laços fortes (amigos, familiares, etc.), capazes de solapar processos racionais de decisão e a busca por eficiência. Livre dos obstáculos advindos do excesso de acoplamento, o empreendedor possuiria maior autonomia de ação.

É possível observar, à luz da possível associação entre OE e Redes, como o desenvolvimento de empreendimentos religiosos poderia, teoricamente, ser o resultado da combinação de dois fatores fundamentais: o primeiro se refere à capacidade de os pastores atuarem como empreendedores. Eles possuiriam, conforme evidências iniciais projetadas por diferentes pesquisadores da sociologia e da religião no Brasil, habilidades para combinarem, sob distintos graus, comportamentos associados à capacidade de inovação, proatividade, agressividade competitiva, assunção de riscos e autonomia. O segundo, por sua vez, relacionase à capacidade de os pastores e o de suas igrejas neopentecostais eventualmente obterem equilíbrio sócio estrutural, ou seja, adequado ajuste entre acoplamento e desacoplamento sociais, considerado por Granovetter (2009) fundamental aos empreendimentos bem-sucedidos, religiosos ou não.

Ao mesmo tempo, é possível notar como as reflexões sobre OE e acoplamento/desacoplamento no contexto religioso poderiam, teoricamente, serem associadas em quadro de análise integrado, totalmente inédito, eventualmente capaz de possibilitar melhor compreensão da dinâmica envolvida na atuação de pastores enquanto empreendedores. Tal como aqui proposto, tal atuação poderia ser o resultado da influência combinada de dois fatores: o primeiro seria o de pastores apropriarem-se de atributos da OE. O segundo seria o de pastores e suas igrejas obterem adequado equilíbrio da estrutura social. Este se constituiria, tal como previsto por Granovetter (2009), por fortes laços entre membros, necessários à criação e repartição internas de importantes recursos (solidariedade horizontal), e parcial distanciamento societário, necessário para evitar solicitações excessivas (solidariedade descontrolada).

\section{Base Metodológica}

A pesquisa de campo foi conduzida com 19 pastores responsáveis pela criação e condução de igrejas neopentecostais independentes localizadas na região metropolitana de Belo Horizonte. Embora possam criar grandes denominações, a exemplo da Igreja Universal do Reino de Deus, considerada uma das responsáveis por liderar o surgimento do que se pode chamar de "igrejas-empresas" (Mariano, 2003, p. 120), tais empreendedores religiosos inseremse, sobretudo, em "pentecostalismo autônomo [responsável por] forma[r] comunidades pequenas e independentes espalhadas principalmente pela periferia dos grandes centros urbanos e organizadas, [sobretudo,] em torno dos atributos carismáticos de seus líderes" (Pacheco et al., 2007, p. 55, grifo nosso).

Os nomes dos pastores foram, por motivações éticas, modificados. O número de pastores se baseou na "saturação ou redundância teórica" (Godoi \& Mattos, 2006; Yin, 2010), obtida quando não se encontraram informações incrementais relevantes. A definição dos casos foi baseada nos objetivos de pesquisa (Yin, 2010). A seleção das unidades empíricas de análise foi fundamentada na "amostragem intencional" (Ridder, Hoon, \& McCandless, 2009) e levou em consideração três aspectos: i.) técnica da bola de neve (Godoi e Mattos, 2006), em que pastores indicaram novos entrevistados; ii.) Acessibilidade, e; iii.) Localização. 
A estratégia de pesquisa foi qualitativa (Creswell, 2007). O método empregado foi o estudo de caso (Yin, 2010), considerado adequado às categorias de interesse, dentre as quais se inseriram as redes, cujas análises são complexas (Halinen \& Törnroos, 2005). A finalidade foi descritiva (Ridder et al., 2009; Yin, 2010), indicada às investigações, como esta, que visam descrever o fenômeno em seu contexto de atuação. De fato, buscou-se através de descrição completa o que Geertz (1989) denominou de thick description. O tipo de projeto foi múltiplo (Aaboen et al., 2012; Ridder et al., 2009; Yin, 2010).

A coleta de dados se fundamentou, a cada um dos pastores, em duas etapas. A primeira, na $\mathrm{OE}$ dos pastores, isto é, em suas habilidades em atuarem como empreendedores. A segunda no arcabouço social das igrejas, nos recursos e atributos advindos de sua estrutura institucional. A estas foi empregada a entrevista semiestruturada em profundidade, considerada uma das mais importantes técnicas de coleta de evidências (Yin, 2010).

A análise, considerada uma das etapas mais difíceis dos estudos de caso (Yin, 2010), compreendeu no "exame, na categorização [e] tabulação das evidências [...] para tirar conclusões baseadas empiricamente" (Yin, 2010, p 154). Foi empregada a "generalização analítica" (Yin, 2010). A técnica indutiva específica se fundamentou na síntese cruzada dos dados (Yin, 2010). Empregou-se a técnica da análise de conteúdo (Bardin, 1977; Mozzato \& Grzybovski, 2011). À categorização das entrevistas foram utilizados, tal como sugerido por Duarte (2002), critérios flexíveis, definidos com base nos objetivos do estudo. Da etapa de categorização dos dados, geraram-se três níveis hierárquicos. $\mathrm{O}$ primeiro, mais amplo, comportou 10 rubricas. Os segundo e terceiro, mais estreitos, 53 e 34, respectivamente. Cada frase ou parágrafo das entrevistas foi alocado em um registro, não excludente, formado pela combinação das rubricas dos três níveis hierárquicos. Um trecho poderia se inserir em mais de uma categoria. Foram gerados 2.085 registros, utilizados como referência à comparação entre casos.

\section{$4 \quad$ Resultados Obtidos}

Igrejas evangélicas competem entre si. "Tem concorrência sim. Não existe outra palavra" (Fernando). Os pastores "entendem que a igreja que tem outra placa é [...] concorrente. A minha igreja é que salva, a minha [...] é que cura, a minha [...] é que vai te levar para o céu" (Benedito). Neste contexto, "a visão é [...] de empresa" (Benedito). É comum "igrejas grandes querendo engolir as pequenas" (Edmundo). Tal competitividade religiosa se associa a outro fenômeno: a vontade dos pastores em crescer suas igrejas. Salienta Damião, por exemplo, como "o reino de Deus [...] tem que ser multiplicado. Se tem 50, tem que ter 100 . Se tem 100 , tem que ter 200. É obrigação nossa gerar almas. Deus pede filhos".

Ambos acabam por implicar aos pastores neopentecostais comportamento empreendedor. Com efeito, pastores neopentecostais podem ser considerados empreendedores. Eles influenciam o desempenho de suas instituições com seu comportamento. A capacidade de inovação, por exemplo, possibilita a formatação de novos serviços caracterizados, no contexto religioso, por parcial ineditismo. Inserem-se, aí: a.) oferta de empregos; b) queda no percentual de dízimo. Inovadora, acolhe às pretensões daqueles que buscam pagar menos pelos serviços religiosos. "Se você [...] descobre que 
pode pagar dízimo de 9,5\% e receber as mesmas bênçãos de quem paga 10\%. [...]. Melhor oferta pelo mesmo serviço" (Humberto); c.) campanhas, dentre as quais se inserem a da revelação. Visa "dizer o que vai acontecer na sua vida daqui um tempo" (Abelardo). Nela, salienta Abelardo, pastores "manipulam o fiel de outra igreja para sair de lá".

A proatividade dos pastores, o pioneirismo em suas ações (Lumpkin \& Dess, 1996; Wiklund \& Shepherd, 2005), é observada, por exemplo, na busca pela conversão de fiéis. Ao visarem isto, acabam por se apropriarem de estratégias à frente de seus concorrentes, antecipando a eles demanda religiosa (Wang, 2008). Para isto, pastores evangelizam de porta em porta (Kaio; Osvaldo; Pedro), ajudam fiéis católicos, promovem encontros de casais não evangélicos (Edmundo; Kaio; Marcelo; Osvaldo; Raimundo; Valdomiro; Zulmira), criam eventos em espaços públicos, entre outros. Já a agressividade competitiva dos pastores, a "intensidade para superar concorrentes" (Lumpkin \& Dess, 2001, p. 431), evidencia-se na busca dos pastores por dois objetivos fundamentais: crescimento das igrejas e manutenção dos fiéis.

O primeiro se observa na intenção de pastores de tirar fiéis de outras igrejas evangélicas. Argumenta Fernando como "é mais fácil buscar crente já formado que pegar uma pessoa lá fora pra cuidar". Entre pastores, é comum frases do tipo: "fulano [...] tá (sic) tirando [...] ovelha do meu aprisco. [...] Eles estão pescando no aquário do outro" (Valdomiro). Para isso, salientam diferentes entrevistados, pastores visitam lideranças religiosas de outras igrejas, manipulando-as (Abelardo; Edmundo; Humberto), convidam fiéis de outros ministérios, oferecendo-lhes vantagens (Fernando), enviam fiéis a demais igrejas, aliciando seus integrantes (Edmundo), entre outros. O segundo se nota nas práticas que visam evitar perda de fiéis. "O maior receio dos pastores [é o de] sua ovelha ir numa outra igreja [...], gostar do alimento que tem lá, ["se sentir melhor" (Humberto)], e ficar lá" (Ulisses). Para isso, proíbem visitas externas (Damião; Edmundo; Kaio; Raimundo; Teodoro; Zulmira), oferecem funções de liderança aos fiéis mais abastados (Edmundo; Humberto), associam visitas a outras igrejas a comportamento não religioso (Osvaldo), enfatizam a igreja como espaço exclusivo para salvação (Humberto), entre outros.

A disposição "para assumir riscos" (Pearce et al., 2010; Wang, 2008) é manifesta, por exemplo, na decisão, ousada, de depender de pastores-auxiliares. Embora eles contribuam para o crescimento das igrejas, uma vez que conseguem fornecer maior atendimento às necessidades dos fiéis, pastores-auxiliares se encontram, também, entre os principais motivos de seus fechamentos. Salientam diferentes pastores como é de brigas entre pastores titulares e auxiliares que ocorrem divisões e fechamento das igrejas. "Já vi muitos casos assim. Vai bucado (sic) com os dissidente (sic) e o restante fica" (Edmundo). "Às vezes, acontece caso de o pastor levar 100\% da igreja" (Raimundo).

Além disso, a capacidade dos pastores em assumirem riscos se evidencia, também, nas práticas prosélitas, sujeitas a retaliações dos concorrentes, e naquelas que visam evitar perdas de fiéis. Muitas vezes coercitivas, dotam-se de ousadia por surtirem efeitos adversos aos planejados. Com efeito, é em parte por causa delas que fiéis saem da "presença do Senhor" (Cristiano). Atualmente, pastor "sabe que se começar com muita exigência, [corre o risco de] o cara não vai ficar" (Marcelo). Finalmente, a autonomia dos pastores, sua disponibilidade em agir de maneira livre (Lumpkin \& Dess, 1996), pode ser evidenciada em praticamente todas as suas ações. Os próprios critérios de seleção, que incorporaram 
pastores responsáveis pela criação e condução de seus empreendimentos, contribuíram para isso.

Mas, a atuação dos pastores parece ainda influenciada por outro conjunto de evidências, de natureza relacional. Pastores constroem e sustentam com seus fiéis coesas redes de relacionamentos. Esta é "uma das características do povo evangélico" (Abelardo). "A gente ajuda muito um ao outro" (Leonardo). Desta estrutura, parecem obter dois conjuntos de atributos fundamentais. O primeiro se associa a densa relação de mútuaassistência manifesta, sobretudo, em dois grupos fundamentais: a.) entre fiéis. "Os irmãos [...] se preocupam muito uns com os outros" (Jeferson). "É um (sic) pelos outros [...]. Se uma ovelha $[\ldots]$ necessita de $[. .$.$] ajuda, aonde que ela vai? Ela vai para a igreja"$ (Cristiano), e; b.) entre fiéis e pastores. Desta relação, pastores obtêm com fiéis recursos associados às esferas pessoal e profissional.

Em relação ao âmbito pessoal, salienta Abelardo como "não é vergonha para um pastor [pedir ajuda aos fiéis] . [...] Isso não desmerece ninguém. (Abelardo). "Eu procurei um amigo. Deixa eu te falar [...] uma coisa: tem jeito de você tirar um carro pra mim? Eu tava (sic) desempregado. [...] Ele foi lá, fez a ficha, a ficha foi aprovada" (Leonardo). Em relação ao contexto profissional, pastores obtêm dos fiéis recursos necessários à criação e ao desenvolvimento de suas igrejas. "Hoje, tudo que nós tamo (sic) conseguindo na igreja, adquirir as coisas, [é] através deles" (Kaio). "Igreja não se faz assim: tenho dinheiro, vou construir. Não existe isso! Quem pensar em fazer isso, tá (sic) indo pro (sic) caminho errado. [...] Precisa haver participação de todos que estão enganjados (sic) nesse trabalho" (Teodoro).

O segundo conjunto de atributos, por sua vez, relaciona-se à possibilidade de evitar a solidariedade descontrolada. Isso porque, a relação de mútua-ajuda é circunscrita. Pastores e fiéis interagem, quase exclusivamente, com membros da mesma igreja. Salienta Humberto como eles se assemelham às "tribos urbanas, [cujos membros] só se relacionam entre si. [...] Só que isso é [ainda] mais nítido na igreja, porque dura [a] vida toda" (Humberto). Disto resulta dois fatos principais. O primeiro é o que a densa rede de solidariedade se destina, principalmente, aos "irmãos de fé", aos frequentadores do mesmo templo. "A prioridade, sempre, são os da casa" (Jeferson). "A própria bíblia pede para a gente ajudar os domésticos da fé" (Abelardo). "É um mandamento bíblico" (Benedito). O segundo é o de que pessoas não acopladas sob mesma coletividade religiosacongregacional, incluindo familiares e demais indivíduos (Abelardo, Sebastião), evangélicos ou não, demonstram-se incapazes de usufruir, de maneira abusiva, dos recursos e benefícios edificados pelas estruturas ministeriais. "Muitas [...] acham que aquilo é só pra ela. Esse comportamento não mudou. É bem humano. Só pra ela. Só para o meu grupo. Meu grupo é mais importante que os outros" (Humberto).

\section{$5 \quad$ Discussã̃o}

Dados de campo parecem sustentar a coerência de algumas constatações. Cinco delas são de destaque. A primeira é que pastores neopentecostais atuam como empreendedores, apropriando-se, em diferentes graus, de atributos derivados da OE. Ao mesmo tempo, seu comportamento empreendedor parece associado ao desempenho de suas 
igrejas. Com efeito, este estudo evidenciou isto. É em grande medida devido às suas capacidades em combinarem capacidade de inovação, proatividade, agressividade competitiva, assunção de risco e autonomia que pastores conseguem novos membros, impedem a egressão de fiéis - atalhando o crescimento de igrejas concorrentes -, e obtêm recursos, sobretudo financeiros, fundamentais às esferas pessoal e profissional. Logo, dados de campo parecem sugerir a proposição que pastores mais empreendedores, com maiores habilidades em associarem atributos da OE, possuiriam, em relação aos demais, capacidade destacada em influenciar positivamente o crescimento de suas igrejas.

A segunda constatação associa-se à estrutura relacional. Evidências de campo parecem sugerir que pastores e igrejas neopentecostais conseguem apropriado ajuste entre acoplamento/desacoplamento. Obtêm dele importantes benefícios. Dois deles podem ser destacados. O primeiro benefício é impedir a solidariedade descontrolada, manifesta nos excessos de pedidos advindos de pessoas, familiares ou não, externas às suas estruturas. Com efeito, ao criarem nos limites das igrejas as fronteiras de sociabilidade e solidariedade, acabam por solapar de pessoas externas solicitações excessivas. O segundo benefício é impulsionar a coesão social das igrejas, estimulando, sobretudo entre seus membros, intensa estrutura de auxílio-mútuo (solidariedade horizontal). Logo, dados de campo parecem sugerir que igrejas e pastores capazes de obter estabilidade de suas estruturas sociais - isto é, adequado ajuste entre acoplamento/desacoplamento sociais possuiriam, em relação aos demais, habilidades distintivas ao desenvolvimento de suas congregações.

A terceira constatação relaciona-se à influência da dimensão social sobre a comportamental. Análises de pesquisa permitem propor que a estrutura social das igrejas influencia a $\mathrm{OE}$ dos pastores. Diferentes evidências empíricas dão sustentação a isto: (a) oclusão estrutural - capaz de impedir o crescimento congregacional, pastores evitaram-na através da busca pelo crescimento de suas igrejas. Para isto, empregam estratégias proativas, agressivas e arriscadas. Proativas ao converter pessoas. Agressivas ao buscar em ministérios concorrentes novos fiéis. Arriscadas ao se verem, muitas vezes, obrigados a dependerem de pastores auxiliares, reconhecidos como um dos responsáveis pelas divisões ministeriais; (b) perda de membros da igreja - para evitá-la, pastores diminuem sua "agressividade competitiva". De fato, salienta Marcelo como pastor "sabe que se começar com muita exigência, [corre o risco de] o cara não vai ficar" (Marcelo). Observe como o arcabouço social das igrejas, manifesta na busca pela sua manutenção e pelo seu crescimento, acabaria por influenciar, em parte, a natureza do comportamento empreendedor dos pastores. Esta é importante constatação de pesquisa. Ao analisar o construto da OE sob variável dependente, salienta-se os benefícios de associá-lo a fatores sócio estruturais ainda pouco enfatizados por pesquisadores da área.

A quarta constatação, em analogia à anterior, associa-se à influência da dimensão comportamental sobre a relacional. Análises de campo permitem edificar ser o comportamento empreendedor capaz de influenciar o arcabouço relacional das congregações. Com efeito, é através da combinação entre capacidade de inovação, proatividade e agressividade competitiva que pastores-empreendedores conseguem, por meio da conversão e do proselitismo, novos membros às suas igrejas. Ou, ainda, é da combinação entre a capacidade de inovação e agressividade competitiva que pastores 
evitam/desestimulam a egressão de fiéis e açodam o adequado adensamento de suas redes congregacionais, impulsionam-nos a restringirem nestas suas interações sociais. Fazem isto ao ensinarem os fiéis a procurarem nos "irmãos de fé" o auxílio necessário (Cristiano); ao salientarem a primazia da família congregacional em detrimento à familiar (Abelardo, Sebastião); ao estimularem a união dos fiéis visando nela apoio necessário ao crescimento de suas igrejas; ao impedirem membros de visitarem igrejas concorrentes (Damião; Edmundo; Kaio; Raimundo; Teodoro; Zulmira), entre outros.

É possível observar, portanto, como pastores parecem capazes de, por meio de seu comportamento empreendedor, influenciar o adequado equilíbrio de seu acoplamento/desacoplamento. De fato, os comportamentos empreendedores que restringem à coletividade congregacional irrestrita gama de auxílio-mútuo, são os mesmos que, devido esta, delimitam aos membros das igrejas seu alcance de sociabilidade, evitando de demais pessoas, familiares ou não, manifestação da solidariedade descontrolada. Esta é importante contribuição. Com efeito, poucos são os estudos (Hoang \& Antoncic, 2003) que salientam as redes como variáveis dependentes, projetando luzes, como aqui realizado, sobre a influência dos processos empreendedores para sua criação/modificação/aperfeiçoamento. A Figura 1, a seguir, ilustra a natureza da reflexão. Apresenta associações, aqui empreendidas, entre OE e rede social.

Figura 1. OE e estrutura social para o crescimento das igrejas.

Atuação de pastores-empreendedores se daria pela

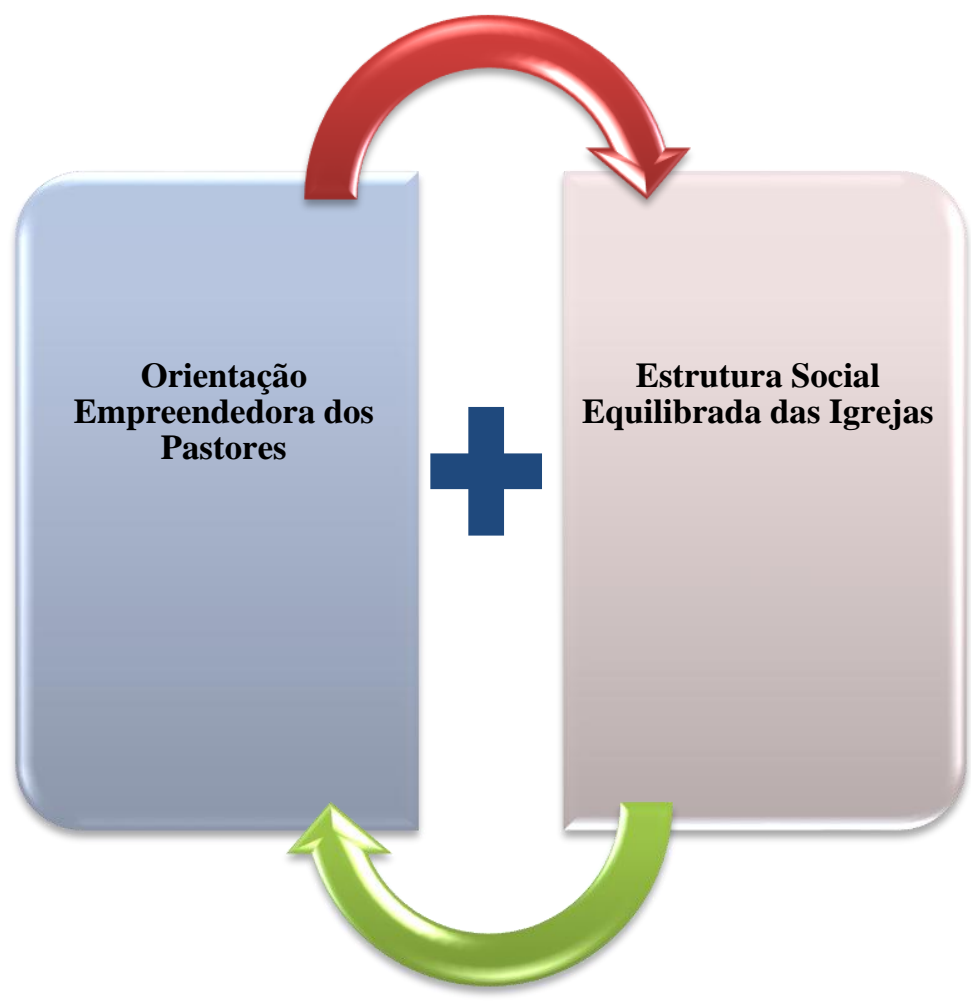


Observa-se, a partir da Figura 2, em síntese, como o processo de desenvolvimento das igrejas neopentecostais se demonstrou, aqui, altamente dinâmico. O comportamento empreendedor dos pastores influenciou a estrutura de suas igrejas. Esta, por sua vez, interferiu na $\mathrm{OE}$ dos pastores, implicando-os à, de maneira passiva, responder através de atributos empreendedores aos imperativos sócio estruturais. Ambos, de maneira cíclica, influenciaram a busca pelo crescimento das igrejas. Logo, análises permitem edificar a constatação que o desenvolvimento de congregações neopentecostais pode ser mais bem compreendido como o resultado da associação positiva entre as duas dimensões.

No entanto, há algo além. Análises complementares permitem avançar mais, projetando luzes para outra consideração de potencial relevância teórica. Original, amplia concepção vigente sobre atributos constituintes da OE. Complementarmente aos pesquisadores da área, que sustentam ser o construto "conjunto de [métodos, práticas (Lumpkin \& Dess, 1996; Wiklund \& Shepherd, 2005)] e comportamentos que possuem como qualidades capacidade de inovação, proatividade, agressividade competitiva, tomada de risco e autonomia, análises aqui obtidas parecem permitir poder eventualmente incluir ao construto da OE atributo adicional: a habilidade para equilibrar estruturas sociais.

\section{Considerações Finais}

Este artigo, resultado de pesquisa teórico-empírica, investigou possíveis associações, ainda pouco exploradas pela literatura, entre as abordagens da OE e a das Redes Sociais. Fez isto através do estudo empírico de tipo particular de empreendedor, o religioso, aqui expresso no papel desempenhado por pastores neopentecostais. Foram coletados e analisados dados de 19 pastores e de suas respectivas igrejas independentes. Evidências permitem edificar importantes conclusões.

A primeira é a de que empreendedores não são essencialmente atomizados/autossuficientes, mas, atores imersos em estruturas de redes socioeconômicas, que influenciam e condicionam suas ações. Este estudo, ao explorar o campo empírico do empreendedorismo religioso, altamente emergente e ainda pouco explorado por analistas organizacionais no Brasil, acaba por endossar a crescente vertente de pesquisa, ainda em evolução, que sustenta a proposição do empreendedor como socialmente posicionado e imbricado. A segunda é que a literatura sobre $\mathrm{OE}$ ganharia robustez e poder explicativo com a associação, ainda limitada, à literatura das redes sociais. Este artigo, ao associar ambas as abordagens, permitiu novas proposições, aqui apenas esboçadas.

Neste sentido, novas pesquisas teóricas e teórico-empíricas necessitam ser realizadas, valorizando-se as abordagens qualitativas. Elas poderiam: a.) ampliar a compreensão das redes sociais na formação de atributos empreendedores; b.) comparar a $\mathrm{OE}$ de pastores neopentecostais e tradicionais, relacionando-a à trajetória de suas instituições; c.) investigar, longitudinalmente, o desempenho de igrejas conduzidas por pastores empreendedores e não empreendedores, projetando luzes sobre as repercussões de suas manifestações; d) pesquisar fatores pessoais e relacionais que interferem no equilíbrio das redes, entre outras. O campo é fértil. Há oportunidades para instigantes descobertas.

\section{Referências}


Adel, G. \& Habib, A. (2016). Mediating Role of Entrepreneurial Orientation on the Relationship Between Relational Network and Competitive Advantages of Tunisian Contractors. J Knowl Econ. p. 1-15.

Bardin, L. (1977). Análise de Conteúdo (1a ed.). Lisboa: Edições 70

Baron R. A. (2013). Enhancing Entrepreneurial Excellence: Tools for Making the Possible Real. Edward Elgar Publishing: Cheltenham, U.K.

Boso, N., Story, V. M., \& Cadogan, J. W. (2013). Entrepreneurial orientation, market orientation, network ties, and performance: Study of entrepreneurial firms in a developing economy. Journal of Business Venturing, 28, 708-727

Carlsson, B. et al. (2013). The evolving domain of entrepreneurship research. Small Business Economics, 41(4), p. 913-930.

Chen, Y., Zhou, X. (2017). Entrepreneurial Self-Efficacy and Firms' Innovation Behavior: the negative mediating role of Social Capital. Social Behavior and Personality, 45(9), 1553-1562.

Colbari, A. L. (2007). A retórica do empreendedorismo e a formação para o trabalho na sociedade brasileira. SINAIS - Revista Eletrônica, 1(1), 75-111.

Corrêa, V. S., \& Vale, G. M. V. (2014). Redes sociais, perfil empreendedor e trajetórias. Rausp, 49(1), 1-13.

Corrêa, V. S., \& Vale, G. M. V. (2017a). Ação Econômica e Religião: igrejas como empreendimentos no Brasil. Revista de Administração Contemporânea, 21(1), 1-18.

Corrêa, V. S., \& Vale, G. M. V. (2017b) Estrutura social e empreendedorismo religioso: uma associação teórica social. Revista de Administração IMED, 7(2), p. 308-322.

Costa, A. M., Barros, D. F., \& Martins, P. E. M. (2012). Cad. EBAPE.BR, 10(2)

Creswell, J. W. (2007). Projeto de Pesquisa: métodos qualitativo, quantitativo e misto (pp. 184-210). Porto Alegre: Artmed

Duarte, R. (2002). Pesquisa qualitativa: reflexões sobre o trabalho de campo. Cadernos de Pesquisa, 115, 139-154.

Estrin, S., Mickiewicz, T., \& Stephan, U. (2016). Human capital in social and commercial entrepreneurship. Journal of Business Venturing 31, p. 449-467.

Ferrary, M. \& Granovetter, M. (2009). The Role of venture capital firms in Silicon Vallley's complex innovation network. Economy and Society, 38(2), 326-359.

Finke, R., Guest, A.M., \& Stark, R. (1996). Mobilizing local religious markets: Religious pluralism in the empire state, 1855 to 1865. American Sociological Review, 61(1), 203-218.

Granovetter, M. (1973). The strength of weak ties. American Journal of Sociology, 78(6), $1360-1380$.

Granovetter, M. (2009). The Economic Sociology of Firms and Entrepreneurs. In R. Swedberg (Ed.), Entrepreneurship: the social science view (pp. 244-275). Oxford University Press: New York

Halinen, A., \& Törnroos, J. (2005). Using case methods in the study of contemporary business networks. Journal of Business Research, 58(9), 1285-1297.

Hmieleski, K. M., Carr, J. C., \& Baron, R. A. (2015). Integrating Discovery and creation perspectives of entrepreneurial action: Strategic Entrepreneurship Journal Strat. Entrepreneurship J., 9, p. 289-312. 
Lajqi, S., \& Krasniqi, B. A. (2017). Entrepreneurial growth aspirations in challenging environment: the role of institutioal quality, human and social capital. Strategic Change, 26(4), $385-401$.

Liu, C., \& Lee, T. (2015). Promoting entrepreneurial orientation through the accumulation ofsocial capital, and knowledge management. International Journal of Hospitality Management. 46, p. 138-150.

Lumpkin, G. T., \& Dess, G. G. (1996). Clarifying the entrepreneurial orientation construct and linking it to performance. Academy of Management Review, 21(1), 135-172.

Lumpkin, G. T., \& Dess, G. G. (2001). Linking two dimensions of entrepreneurial orientation to firm performance: the moderating role of environment and industry life cycle. Journal of Business Venturing, 16(5), 429-451.

Mariano, R. (2013). Antônio Flávio Pierucci: sociólogo materialista da religião. Revista Brasileira de Ciências Sociais, 28(81), 7-16.

Martinelli, A. (2009). O contexto do empreendedorismo. In A. Martinelli, B. Lévesque, \& C. Kirschbaum (Eds.), Redes e Sociologia Econômica: (pp. 207-237). Edufscar

Martins, I. (2016). Network Usage, Entrepreneurial Orientation and Their Effectiveness on SMEs Growth. The Journal of Entrepreneurship 25(1), p. 18-41.

McClelland, D. C. (1972). A sociedade competitiva. Rio de Janeiro: Expressão e Cultura

Moroz, P. W., \& Hindle, K. (2012). Entrepreneurship as a process: toward harmonizing multiple perspectives. Entrepreneurship Theory and Practice, 36(4), p 781-818.

Mozzato, A. R., \& Grzybovski, D. (2011). Análise de conteúdo como técnica de análise de dados qualitativos no campo da Administração. Revista de Administração Contemporânea, 15(4), 731-747.

Nair, K. R. G., \& Pandey, A. (2006). Characteristics of entrepreneurs: an empirical analysis. Journal of Entrepreneurship, 15(1), 47-61.

Nobile, D., \& Husson, J. (2016). Entrepreneurial orientation in local authorities. International Journal of Technology Management \& Sustainable Development, 15(2).

Nwankwo, S. \& Gbadamosi, A. (2013). Faith and entrepreneurship among the British African-Caribbean: Intersections between religious and entrepreneurial value. Journal of Small Business and Enterprise Development, 20(3), 618-633.

Pacheco, E. T., Ribeiro da Silva, S., \& Ribeiro, R. G. (2007). "Eu era do mundo": tranformações do auto-conceito na conversão pentecostal. Psicologia: Teoria e Pesquisa, 24(1), 53-62.

Passos, M., Zorzin, P. L. G., \& Rocha, D. (2011). O que (não) dizem os números - para além das estatísticas sobre o "Novo Mapa das Religiões Brasileiro". Horizonte, 9(23), 690-714.

Pearce, J. A., Fritz, D. A., \& Davis, P. S. (2010). Entrepreneurial Orientation and the Performance of Religion Congregations as Predicted by Rational Choice Theory. Entrepreneurship Theory and Practice, 34(1), 219-248.

Pierucci, A. F. (1999, dezembro 26). Fim da união Estado-Igreja ampliou oferta de religiões. Folha de São Paulo, Caderno Especial.

Pierucci, A. F. (2008). De olho na modernidade religiosa. Tempo Social, revista de sociologia da USP, 20(2), 9-16. 
Pierucci, A. F. (2011). Religiões no Brasil. In A. Botelho, \& L. M. Schwarcz (Orgs.), Agenda Brasileira: temas de uma sociedade em mudança (Cap. 41, pp. 470-479). São Paulo: Companhia das Letras

Ribeiro-Soriano, D. (2017). Small business and entrepreneurship: their role in economic and social development. Entrepreneurship \& Regional Development, 29(1-2), p. 1-3.

Ridder, H., Hoon, C., \& McCandless, A. (2009). The theoretical contribution of case study research to the field of strategy and management. Research Methodology in Strategy and Management, 5, 137-175.

Saeed, S., Yousafzai, S. Y., \& Engelen, A. (2014). On cultural and macroeconomic contingencies of the entrepreneurial orientation-performance relationship. Entrepreneurship: Theory and Practice, 38, 255-290.

Schumpeter, J. A. (1911) The Theory of Economic Development. 1. ed. Oxford: Oxford University Press, 1961.

Shan, P., Song, M., \& Ju, X. (2016). Entrepreneurial orientation and performance: Is innovation speed a missing link? Journal of Business Research 69, p. 683-690.

Shepherd, D. (2015). Party On! A call for entrepreneurship research that is more interactive, activity based, cognitively hot, compassionate, and prosocial. J. Bus. Ventur. 30 (4), 489-507.

Shook, C. L., Priem, R. L., \& McGee, J. E. (2003). Venture Creation and the Enterprising Individual: A Review and Synthesis. Journal of Management, 29(3), 379-399.

Simsek, Q. C. Z., \& Jansen, J. J. P. (2015). CEO Social Capital and Entrepreneurial Orientation of the Firm: Bonding and Bridging Effects. Journal of Management, 41(7), p. 19571981.

Smith, C., Smith, J. B., \& Shaw, Eleanor (2017). Embracing digital networks: Entrepreneurs' social capital online. Journal of Business Venturing Journal of Business Venturing 32, p. 18-34.

Song, G., Min, S. Lee, S. \& Seo, Y. (2017). The effects of network reliance on opportunity recognition: A moderated mediation model of knowledge acquisition and entrepreneurial orientation. Technological Forecasting \& Social Change, 117, 98-107

Stam, W., Arzlanian, S., \& Elfring, T. (2014). Social capital of entrepreneurs and small firm performance: a meta-analysis of contextual and methodological moderators. J. Bus. Ventur. 29(1), p. 152-173.

Suyanto.; Pratono, A. H. (2016). Entrepreneurial Orientation and Social Capital in Pricing Strategy: a case of small enterprises in East Java. Jurnal Ekonomi dan Bisnis. 18(3),

Urbano, D., \& Aparicio, S. (2016). Entrepreneurship capital types and economic growth: International evidence. Technological Forecasting \& Social Change, 102, 34-44.

Vale, G. M. V. (2014). Empreendedor: origens, concepções teóricas, dispersão e integração. Revista de Administração Contemporânea, 18(6), p. 874-891.

Williams, N., Huggins, R., \& Thompson, P. (2017). Social Capital and Entrepreneurship: Dos the relationship hold in deprived urban neighbourhoods? Growth and Change, 48(4), 719743.

Yin, R. K. (2010). Estudo de Caso: planejamento e métodos. Porto Alegre: Bookman 